\title{
Residuos urbanos, agrícolas y pecuarios en el contexto de las biorrefinerías
}

\author{
James Andrés Gómez-Soto ${ }^{1}$ \\ Óscar Julián Sánchez-Toro² \\ Luis Gerónimo Matallana-Pérez ${ }^{3}$
}

Fecha de recepción: 5 de junio de 2019

Fecha de aprobación: 13 de agosto de 2019

\section{Resumen}

La generación de residuos se está incrementando a nivel global y su deficiente aprovechamiento provoca serios problemas ambientales, económicos y sociales. El objetivo del presente trabajo fue analizar el estado del arte de los residuos sólidos urbanos, agrícolas y pecuarios en cuanto a cantidad y composición, así como analizar el concepto de biorrefinerías desde su diseño como una alternativa sostenible para el aprovechamiento de materias primas residuales. La consulta de la información se realizó en diferentes bases de datos como Web of Science, Scopus y Google Scholar. El análisis de la información permitió identificar que los residuos se producen en cantidades considerables y poseen compuestos orgánicos de valor, que son aprovechados en mayor o menor proporción de acuerdo con factores tecnológicos, culturales y socio-económicos en cada región particular. Son necesarias nuevas políticas para la gestión integral de los residuos sólidos que integren el concepto de biorrefinerías desde la generación y separación en la fuente hasta su aprovechamiento y disposición final. La implementación adecuada de procesos físicos, termoquímicos, químicos y biológicos bajo el concepto de biorrefinerías puede recuperar o transformar de forma integral las materias primas residuales para la obtención de productos como biocombustibles, alimentos y energía. Se hace necesario diseñar biorrefinerías para determinar su viabilidad en el aprovechamiento de los residuos. Explorar este tipo de alternativas evaluando diferentes factores (tecno-económico, ambiental y social), puede

\footnotetext{
${ }^{1}$ M. Sc. Universidad de Caldas (Manizales-Caldas, Colombia). james.37916220109@ucaldas.edu.co. ORCID: 0000-0002-2822-0465.

${ }^{2}$ Ph. D. Universidad de Caldas (Manizales-Caldas, Colombia). osanchez@ucaldas.edu.co. ORCID: 0000-00022372-0647.

${ }_{3}^{3} \mathrm{Ph}$. D. Universidad de Caldas (Manizales-Caldas, Colombia). luis.matallana@ucaldas.edu.co. ORCID: $\underline{0000-}$ 0001-8713-0411.

Revista Facultad de Ingeniería (Rev. Fac. Ing.) Vol. 28 (53), pp. 7-32. Octubre-Diciembre 2019. Tunja-Boyacá, Colombia. L-ISSN: 0121-1129, e-ISSN: 2357-5328, DOI: https://doi.org/10.19053/01211129.v28.n53.2019.9705
} 
apoyar la toma de decisiones de inversión e investigación en tecnologías de aprovechamiento para ser implementadas a pequeña o gran escala en regiones de Colombia y el mundo con gran disponibilidad de residuos.

Palabras clave: composición; desarrollo sostenible; diseño; producción; tratamiento de residuos.

\section{Urban, Agricultural and Livestock Residues in the Context of Biorefineries}

\section{Abstract}

The generation of waste is increasing globally and its poor utilization causes serious environmental, economic and social issues. The aim of this work was to analyze the state of the art on urban, agricultural and livestock solid waste in terms of quantity and composition, as well as to analyze the concept of biorefineries from the viewpoint of their design as a sustainable alternative for the use of residual raw materials. The information was consulted in different databases such as Web of Science, Scopus, and Google Scholar. The analysis of the information identified that the residues are produced in considerable amounts and have valuable organic compounds, which are used to a greater or lesser extent according to technological, cultural, and socio-economic factors in each specific region. New policies are needed for the integral management of solid waste that integrates the concept of biorefineries from the generation and separation at the source to its utilization and final disposal. The proper implementation of physical, thermochemical, chemical, and biological processes under the concept of biorefineries can recover or transform in an integral way the residual raw materials to obtain products such as biofuels, food, and energy. Designing biorefineries to determine their viability for waste utilization is required. Exploring this type of alternatives by evaluating different factors (techno-economic, environmental, and social) may support the decision making of investment and research in utilization technologies to be implemented on a small or large scale in regions of Colombia and the world with great waste availability.

Keywords: composition; design; production; sustainable development; waste treatment.

\section{Resíduos urbanos, agrícolas e pecuários no contexto das biorrefinarias Resumo}

A geração de resíduos está incrementando-se a nível global e seu deficiente aproveitamento provoca sérios problemas ambientais, econômicos e sociais. O objetivo do presente trabalho foi analisar o estado da arte dos resíduos sólidos urbanos, agrícolas e Revista Facultad de Ingeniería (Rev. Fac. Ing.) Vol. 28 (53), pp. 7-32. Octubre-Diciembre 2019. Tunja-Boyacá, Colombia. L-ISSN: 0121-1129, e-ISSN: 2357-5328, DOI: https://doi.org/10.19053/01211129.v28.n53.2019.9705 
pecuários referente a quantidade e composição, assim como analisar o conceito de biorrefinarias desde seu desenho como uma alternativa sustentável para o aproveitamento de matérias primas residuais. A consulta da informação realizou-se em diferentes bases de dados como Web of Science, Scopus e Google Scholar. A análise da informação permitiu identificar que os resíduos se produzem em quantidades consideráveis e possuem compostos orgânicos de valor, que são aproveitados em maior ou menor proporção de acordo com fatores tecnológicos, culturais e socioeconômicos em cada região particular. São necessárias novas políticas para a gestão integral dos resíduos sólidos que integrem o conceito de biorrefinarias desde a geração e separação na fonte até seu aproveitamento e disposição final. A implementação adequada de processos físicos, termoquímicos, químicos e biológicos sob o conceito de biorrefinarias pode recuperar ou transformar de forma integral as matérias primas residuais para a obtenção de produtos como biocombustíveis, alimentos e energia. É conveniente desenhar biorrefinarias para determinar sua viabilidade no aproveitamento dos resíduos. Explorar este tipo de alternativas avaliando diferentes fatores (tecno-econômico, ambiental e social), pode apoiar a tomada de decisões de investimento e pesquisa em tecnologias de aproveitamento para serem implementadas a pequena ou grande escala em regiões da Colômbia e do mundo com grande disponibilidade de resíduos.

Palavras chave: composição; desenvolvimento sustentável; desenho; produção; tratamento de resíduos.

\section{Para citar este artículo:}

J. A. Gómez-Soto, O. J. Sánchez-Toro, and L. G. Matallana-Pérez, "Residuos urbanos, agrícolas y pecuarios en el contexto de las biorrefinerías," Revista Facultad de Ingeniería, vol. 28 (53), pp. 7-32, Oct. 2019. https://doi.org/10.19053/01211129.v28.n53.2019.9705.

\section{Esta obra está bajo licencia internacional Creative Commons Reconocimiento 4.0}

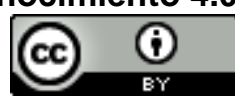




\section{INTRODUCCIÓN}

La generación de residuos sólidos en la próxima década aumentará en todo el mundo. A nivel mundial, más de 300 millones de toneladas de residuos sólidos urbanos (RSU) por año se disponen en rellenos sanitarios y solo 140 millones aproximadamente son reciclados [1]. La tasa de reciclaje de RSU en algunos países como Canadá, China y Alemania es de aproximadamente el $27 \%$, $30 \%$ y $47 \%$, respectivamente [2]. En Colombia, solo se aprovecha aproximadamente el $17 \%$ de los residuos totales que se generan [3]. La mayoría de los residuos sólidos son enviados a rellenos sanitarios [1], dispuestos en lugares no adecuados [4] o dejados en las parcelaciones agrarias para su descomposición [5].

Una fracción mayoritaria de los residuos sólidos corresponde a la biomasa residual [1]. La biomasa residual se define como los materiales orgánicos renovables generados en diferentes actividades (urbanas, agropecuarias y agroindustriales) e incluyen residuos municipales, de alimentos y forestales, entre otros [6]. La biomasa residual es atractiva para su aprovechamiento porque sus biomoléculas (proteínas, lípidos, carbohidratos y minerales) se pueden recuperar o transformar por medio de diferentes procesos de conversión a múltiples productos [7-9].

Las tecnologías utilizadas para el procesamiento de la biomasa residual son un conjunto de procesos físicos, termoquímicos, químicos y biológicos que permiten obtener diferentes productos de valor a partir de la composición propia de la biomasa relacionada con las condiciones de operación de cada proceso $[9,10]$. En este sentido, la biomasa residual representa nuevos retos para la humanidad en su aprovechamiento sostenible. La sostenibilidad se define como el acto de mantener o mejorar las condiciones sociales y materiales para la salud humana y el medio ambiente a lo largo del tiempo sin exceder las capacidades ecológicas que las sustentan [11].

La implementación de procesos de conversión adecuados para la biomasa residual es una solución al deficiente aprovechamiento de los residuos, en especial, la implementación de estos procesos en el contexto de las biorrefinerías. Las biorrefinerías son sistemas productivos que aprovechan sosteniblemente la 
biomasa para recuperar la mayor cantidad de carbono [12] en diferentes productos comercializables (alimentos, biocombustible y energía, entre otros) [9].

Las biorrefinerías a nivel mundial se orientan por lo general a la producción de biocombustibles y utilizan en su mayoría, materias primas como caña de azúcar, maíz, grasas, aceites y en mínima proporción RSU [13-16].

En Colombia, no se cuenta con biorrefinerías a escala industrial que transforme la biomasa residual. El país cuenta con complejos a nivel industrial con características de biorrefinerías de primera generación (utilizan materias primas alimentarias provenientes de cultivos) [17] que producen alcohol carburante o biodiesel a partir de caña de azúcar o aceite de palma [18].

Se identifica la necesidad de implementar nuevos procesos de transformación o procesos existentes mejorados en el contexto de biorrefinerías de segunda generación (aprovechamiento de los residuos y biomasa lignocelulósica) [17] para recuperar sosteniblemente la biomasa residual urbana, agrícola y pecuaria. El diseño y evaluación de biorrefinerías sostenibles es crucial para apoyar la implementación de este tipo de infraestructuras en diferentes regiones del mundo. De esta forma, se contribuye con procesos que reduzcan el impacto negativo al medio ambiente causado por la humanidad y con la transición de una economía lineal a una economía circular como sistema industrial restaurativo; a fin de lograr una sociedad más sostenible [19].

El objetivo del presente trabajo fue analizar las características de los residuos sólidos urbanos, agrícolas y pecuarios como cantidad y composición en el contexto del diseño y evaluación de biorrefinerías.

\section{MATERIALES Y MÉTODOS}

La consulta de la información se realizó en las bases de datos de Scopus, Web of Science y Google Scholar. La consulta tuvo los siguientes criterios: algoritmo de búsqueda aplicado únicamente a el título, el resumen y las palabras claves en cada base de datos; consulta en todos los documentos publicados hasta la fecha; documentos de investigación clasificados como artículos, revisiones, libros, capítulos de libros y documentos escritos en inglés y en español. El algoritmo de 
búsqueda se construyó a partir de palabras claves en inglés como: "Biorefinery"; "Municipal"; "solid"; "waste"; "agricultural"; "livestock"; "use"; "process"; "transformation" y la conjugación de estas palabras en español. Se utilizaron los operadores booleanos AND, OR y el comodín $\left({ }^{*}\right)$ en el algoritmo de acuerdo al procedimiento descrito por Arango et al. [20]. La búsqueda fue acotada a 150 documentos utilizando el procedimiento descrito por Pérez y Muñoz [21]. Los resultados se exportaron a una matriz en una hoja de cálculo en donde se realizó el análisis.

\section{Resultados Y Discusión}

\section{A. Clasificación de los residuos}

Los residuos constituyen un conjunto de materiales desechados tras su vida útil que, por lo general, carecen de valor agregado. Los residuos poseen múltiples compuestos que generan diferentes clasificaciones de acuerdo con su origen: residencial, industrial, comercial, institucional, construcción, servicios municipales, procesos, médicos y de agricultura [1]. A nivel mundial, los residuos se clasifican como peligrosos y no peligrosos [22]. La mayoría de los países poseen un sistema propio de clasificación de los residuos. Por ejemplo, Estados Unidos clasifica sus residuos en residuos sólidos municipales, lodos y residuos industriales, entre otros; adicionalmente, establece las regulaciones en cuanto a su recolección y tratamiento [23]. En la Unión Europea, la clasificación de los residuos posee 20 categorías de acuerdo con su origen $[24,25]$.

En Colombia, el tratamiento de los residuos sólidos está reglamentado por diferentes normas [26-29]. Estos documentos definen la gestión integral de los residuos sólidos, reglamentan su recolección, el transporte, el aprovechamiento y la disposición final, entre otros aspectos. En particular, la Norma Técnica Colombiana GTC 24 [30], define los criterios para la separación de los residuos sólidos en la fuente y los clasifica en residuos no peligros (aprovechables, no aprovechables y orgánicos no biodegradables), residuos peligrosos y residuos espéciales con sus respectivas subclasificaciones. La Guía Técnica Colombia GTC 53-7 [10] clasifica 
los residuos agrícolas y pecuarios dentro de la categoría de los residuos orgánicos no peligrosos y presenta diferentes métodos de aprovechamiento para este tipo de biomasa residual (biológico y termoquímicos, entre otros.).

Existen países que implementan sistemas de clasificación y tratamiento rigurosos enfocados en la recuperación y disposición de los residuos con el menor impacto posible al medio ambiente. Estos países poseen un compromiso social por medio del estricto cumplimiento de las normas sanitarias y por la adopción y el desarrollo de una conciencia ambiental colectiva. Este compromiso, es fundamental para fortalecer la separación en la fuente y cambiar el concepto de residuo por el concepto de materia prima para procesos productivos. Una clasificación rigurosa en la fuente evita la contaminación entre residuos, y permite extraer los materiales orgánicos e inorgánicos separados por clases para ser tratados en diferentes procesos (físicos, químicos, etc.) de forma eficiente.

El desarrollo del compromiso social por medio de la educación en temas relacionados con la reducción, la clasificación y el aprovechamiento primario de los residuos en la fuente (reciclaje), debe ser un factor fundamental a implementarse desde las políticas gubernamentales de los países, especialmente en países de ingresos medios como Colombia. Lo anterior, contribuye con condiciones sanitarias óptimas y con la reducción de la cantidad de materiales que entra o sale del sistema social e impulsa la reutilización de los residuos dentro del mismo sistema [31].

Se identifican dos modelos económicos de producción que se relacionan directamente con el desarrollo de la gestión integral de los residuos. El modelo económico lineal que sigue las etapas de tomar, hacer y disponer; y el modelo económico circular que reemplaza la etapa de disponer por reutilizar. El modelo económico circular representa una oportunidad para que la economía industrial evolucione a una economía restauradora por intención, orientada a confiar en las energías renovables, minimizar, rastrear y eliminar el uso de químicos tóxicos, y erradicar los residuos mediante un cuidadoso diseño [19]. Colombia sigue un modelo económico lineal de producción y esto se evidencia en la deficiente separación en la fuente y el mínimo aprovechamiento de los residuos sólidos [4, 5, 32]. 
Se hace necesario implementar nuevas políticas o apoyar las existentes desde el rediseño de la gestión integral de los residuos sólidos y su aprovechamiento. Realizar estudios más detallados de factores socio-económicos locales, incluyendo la cultura, las prácticas y el comportamiento humano, pueden apoyar el proceso de toma de decisiones para la selección de tecnologías apropiadas en la transformación de las materias primas residuales [33].

\section{B. Generación de residuos}

1) Residuos sólidos urbanos. Entre los años 2012 y 2017, la generación de RSU a nivel mundial fue de aproximadamente 1.882.382.592 toneladas ( $t$ ) por año en promedio [34]; de estos residuos, el $46 \%$ fueron orgánicos. Para el año 2025, se pronostica una generación de RSU de 2,2 mil millones t/año aproximadamente [1]. En Colombia, la disposición final de RSU para el año 2017 fue de 30.081 t/día en promedio (aproximadamente16.545 t/día de residuos orgánicos) [35, 36]. Los departamentos que mayor cantidad de RSU disponen son Antioquia (3.442 t/día), Valle del Cauca (3.382 t/día) y Atlántico (2.766 t/día); Bogotá es la ciudad que más RSU genera (6.265 t/día). En el departamento de Caldas, la generación de RSU para el año 2017 alcanzó las 732 t/día en promedio [36]. La mayoría de estos residuos son enviados a rellenos sanitarios para su disposición final [4, 28].

La generación de RSU puede estar influenciada por la capacidad adquisitiva que poseen las personas para adquirir más fácilmente bienes de consumo. Esta capacidad sesga la evaluación de vida útil por parte del consumidor y hace que desechen más rápidamente los productos. Desde otro punto, el reciclaje se considera un componente clave de las prácticas modernas de reducción de los residuos para mitigar el impacto ambiental negativo [33]. La implementación de nuevas prácticas sociales para la reutilización de los residuos, incluyendo la transformación de los residuos de alimentos en materias primas para diferentes procesos industriales, puede ser una opción de aprovechamiento y reducción de la cantidad de biomasa residual que se dispone. Es necesario implementar estrategias de separación y conservación de este tipo de materia prima residual en la fuente y aplicar una transformación adecuada para que los nuevos productos sean seguros 
en su uso. Por ejemplo, los alimentos que son desperdiciados en las ciudades pueden separarse en grupos (granos vegetales, frutas, carnes, lácteos, etc.), conservarse y ser transformados en productos con características de alimentos para animales a partir de proporciones óptimas de estos residuos.

La reutilización de los residuos inorgánicos (bolsas plásticas, botellas, contenderos, neumáticos, etc.) es otra opción que contribuye con la reducción de la cantidad que se dispone de este tipo de residuos en tierras y cuerpos de agua. Actualmente, existe una visión de aprovechamiento de los residuos plásticos para darles un nuevo uso. Por ejemplo, en el desarrollo de diferentes productos (estibas plásticas, casas prefabricadas, etc.) [37], en el reforzamiento asfaltico, en la producción de monómeros y absorbentes poliméricos, entre otros [38].

2) Residuos agrícolas y pecuarios. La generación de residuos agrícolas a nivel mundial para el año 2016 se proyectó en 368.329.087.469 t aproximadamente [39]. En Colombia, la producción de residuos agrícolas estimada a partir de los cultivos más representativos para el año 2017 fue de 218.007.204 t. De esta cantidad, los cultivos que más residuos generan son la caña de azúcar (155.866.414 t), el plátano (26.547.871 t) y el banano (12.674.307 t) [40, 41]. Una pequeña parte de estos residuos son aprovechados en la elaboración de alimentos para animales, en la producción de biocombustibles y en la elaboración de papel.

De otro lado, la generación de residuos pecuarios a nivel mundial se estimó en aproximadamente 60 millones de t/año. Alrededor de 38,82 millones de toneladas de estos residuos se transforman en subproductos como harina de carne, cebo y harina de sangre del sacrificio de ganado, ovejas, cerdos, pollos y pescado [42]. Solo en Alemania, la generación de residuos a partir de la producción de carne ascendió a 1.249.000 t/año [43]. En la Tabla 1 se presenta el porcentaje aproximado de residuos que se obtienen a partir de diferentes procesos pecuarios.

Tabla 1. Porcentaje de residuos a partir de procesos de producción pecuaria. Adaptado de Hicks y Verbeek [42].

\begin{tabular}{|l|c|}
\hline \multicolumn{1}{|c|}{ Proceso de producción } & Conversión de residuos (\%) \\
\hline Sacrificio de reses & $40-52$ \\
\hline Procesamiento de crustáceos & $50-60$ \\
\hline Conservas de pescado & $30-65$ \\
\hline Fileteado de pescado, curado, salado, ahumado & $50-75$ \\
\hline
\end{tabular}




\begin{tabular}{|l|c|}
\hline \multicolumn{1}{|c|}{ Proceso de producción } & Conversión de residuos (\%) \\
\hline Producción de queso & $85-90$ \\
\hline Procesamiento de moluscos & $20-50$ \\
\hline Sacrificio de cerdos & 35 \\
\hline Sacrificio de aves de corral & $31-38$ \\
\hline Producción de yogur & $2-6$ \\
\hline
\end{tabular}

En Colombia, el sacrificio de ganado (vacuno, bufalino, porcino caprino y ovino) para el tercer trimestre del año 2018 alcanzó un total de 496.445 t (peso en pie); con un rendimiento de la canal para el ganado vacuno y porcino de $52,4 \%$ y $79,7 \%$, respectivamente [44]. El sector avícola en el año 2018 produjo 1.624 .000 t de pollo [45]; el rendimiento de la canal de pollo varía de acuerdo con el peso del animal y se encuentra aproximadamente entre un $71 \%$ y $73 \%$ [46]. La mayoría de los residuos de la industria pecuaria son considerados subproductos y se utilizan como aditivos o materias primas en alimentos o piensos para animales [42].

Existen otros residuos generados en el sector pecuario como aquellos que se producen antes de realizar el beneficio del animal (estiércol, orín, restos de piel o plumaje, restos de alimentación y restos del hábitat, etc.) que son susceptibles de aprovechamiento. Por ejemplo, un cerdo de $110 \mathrm{~kg}$ puede producir $4,6 \mathrm{~kg}$ de residuos (estiércol y orina). En la actividad avícola se producen excretas de la producción de huevos y residuos provenientes de granjas de engorde, con un contenido de materia seca y nitrógeno de $27 \%$ al $41 \%$ y de $1,25 \%$ a $1,5 \%$ respectivamente. En la producción bovina, un novillo de $265 \mathrm{~kg}$ puede producir 13 kg de excremento al día [47]. En la Tabla 2, se presenta una proyección de la producción de estiércol en Colombia que indica la cantidad de este tipo de biomasa susceptible de aprovechamiento.

Tabla 2. Producción de estiércol generado en Colombia para el año 2008. Adaptado de Escalante, et al. [40].

\begin{tabular}{|l|r|}
\hline Residuo Pecuario & Cantidad (t/año) \\
\hline Avícola & 3.446 .348 \\
\hline Bovino & 99.168 .608 \\
\hline Porcino & 2.803 .111 \\
\hline Total & 105.418 .067 \\
\hline
\end{tabular}




\section{Composición de los residuos}

1) Residuos sólidos urbanos. La composición de los RSU está influenciada por factores como la cultura, el desarrollo económico, el clima, las fuentes de energía, frecuencia de recolección y métodos de eliminación [1]. Los RSU a nivel mundial se componen principalmente de desechos orgánicos (Tabla 3). En Colombia, el 61,5 $\%$ de los RSU son materia orgánica (putrescible), el $20 \%$ corresponde a envases y empaques, y el $18,5 \%$ son otros materiales (metálicos, etc.) [32].

Tabla 3. Composición de los RSU por su naturaleza. Adaptado de Hoornweg y Bhada-Tata [1].

\begin{tabular}{|l|l|c|}
\hline \multicolumn{1}{|c|}{ Tipo } & \multicolumn{1}{|c|}{ Fuentes } & Participación (\%) \\
\hline Orgánico & $\begin{array}{l}\text { Desechos de alimentos, residuos de jardín (hojas, hierba, etc.), } \\
\text { madera, fracción orgánica de los residuos sólidos urbano de las } \\
\text { empresas, entre otros }\end{array}$ & 46 \\
\hline Papel & $\begin{array}{l}\text { Desechos de papel, cartón, periódicos, revistas, bolsas, cajas, } \\
\text { papel de envoltura, guías telefónicas, papel triturado y tazas de } \\
\text { papel para bebidas, entre otros }\end{array}$ & 17 \\
\hline Plástico & Botellas, envases, recipientes, bolsas, tapas, tazas, entre otros & 10 \\
\hline Vidrio & Botellas, cristales rotos, bombillas, vasos de colores, entre otros & 5 \\
\hline Metal & $\begin{array}{l}\text { Latas, papel de aluminio, latas, latas de aerosol no peligrosas, } \\
\text { electrodomésticos (artículos blancos), barandillas, bicicletas, } \\
\text { entre otros }\end{array}$ & 4 \\
\hline Otros & $\begin{array}{l}\text { Textiles, cuero, caucho, laminados múltiples, residuos } \\
\text { electrónicos, electrodomésticos, cenizas, otros materiales } \\
\text { inertes, entre otros }\end{array}$ & 18 \\
\hline
\end{tabular}

2) Residuos agrícolas y pecuarios. Los residuos agrícolas pueden contener diferentes tipos de compuestos como almidones con un variado porcentaje de amilosa y amilopectina [48,49], pectinas [50-55], diferentes tipos de proteínas [56, 57] y lípidos como grasas y aceites [58-60], entre otros compuestos. En especial, los residuos agrícolas pueden contener una alta cantidad de material lignocelulósico.

Los materiales lignocelulósicos son un tipo particular de biomasa producida por organismos vivos que contienen energía almacenada del sol. Esta energía se convierte en almidón y celulosa, entre otros compuestos a través de la fotosíntesis [61]. El complejo lignocelulósico representa el material de origen biológico más abundante en la naturaleza. La producción mundial de biomasa de plantas terrestres se estima en 146 mil millones de t/año en promedio [62]. Este tipo de biomasa posee una compleja estructura entrelazada de celulosa, hemicelulosa y lignina [63]. 
La celulosa, es el biopolímero más abundante sintetizado en la tierra [64] con una producción anual de más de $7,5 \times 10^{10} \mathrm{t}$, posee propiedades de carbón neutro [65]. La celulosa es un compuesto de fórmula $\left(\mathrm{C}_{6} \mathrm{H}_{10} \mathrm{O}_{5}\right)_{n}$, es un polisacárido insoluble en agua conformado por varias a cientos de unidades de glucosa unidas por enlaces $\beta-(1,4)[63]$.

La hemicelulosa compone entre el $20 \%$ y $40 \%$ de la biomasa lignocelulósica y consiste en cadenas cortas muy ramificadas de azúcares (200 en promedio) como la xilosa y la arabinosa $[66,67]$.

La lignina representa entre el $10 \%$ y el $25 \%$ de la biomasa lignocelulósica y está compuesta por tres tipos de fenoles (monolignoles) como el alcohol coniferílico, el alcohol sinapílico y el alcohol p-cumarílico [66].

Desde otro punto, los residuos pecuarios se componen principalmente de proteínas y grasas. Entre las proteínas más aprovechadas están las proteínas del lactosuero [68, 69], las proteínas estructurales (colágeno, queratina y fibrillas musculares, entre otros) y las proteínas de transporte (hemoglobina y albumina plasmática). De estos residuos se obtienen diferentes aislados y concentrados de proteína [70], la harina de pluma, la harina de carne y hueso, y la harina de pescado [42], entre otros subproductos.

Las grasas como residuos pecuarios se pueden clasificar en: grasas comestibles y no comestibles. Las grasas no comestibles se utilizan en la producción de biodiesel y energía, entre otros usos. Las grasas comestibles se producen generalmente a partir de subproductos frescos del sacrificio de animales sanos.

Las grasas comestibles distintivas son el sebo de la carne de vaca, la grasa del cerdo, y la grasa del ganso o del pato. Las grasas animales más comunes son las derivadas del sector lácteo (la mantequilla) [71].

En este sentido, se identifica una producción de materias primas residuales urbanas, agrícolas y pecuarios en cantidades significativas con una composición variada que no es aprovechada en su totalidad. Los residuos con un mayor potencial de aprovechamiento son aquellos con un alto contenido de proteína, grasa y almidón, debido a sus características fisicoquímicas y nutricionales. 
La materia prima residual con un alto contenido de material lignocelulósico presente mayoritariamente en la biomasa agrícola, es aprovechada en poca cantidad debido a su compleja estructura [72]. Para la transformación de esta materia prima se requiere emplear procesos complejos de pretratamiento que pueden demandar un mayor tiempo de ejecución e insumos y generar una menor cantidad de productos y mayores costos de producción.

\section{Diseño de procesos para el aprovechamiento de residuos en el contexto de biorrefinerías}

Existen múltiples procesos de aprovechamiento con diferentes grados de complejidad que pueden ser aplicados a la materia prima residual urbana, agrícola y pecuaria (Tabla 4). En la Fig. 1, se presenta el esquema genérico de una biorrefinería. Se destaca de esta estructura, como la materia prima ingresa a una serie de operaciones y procesos unitarios que permiten obtener la mayor cantidad de productos. Los productos intermedios (residuos), ingresan nuevamente a otros procesos para recuperar la mayor cantidad de masa y energía.

La estructura de una biorrefinería está soportada en plataformas de conversión (Fig. 2). Estas plataformas están relacionadas directamente con la composición de la biomasa residual. La composición de la biomasa permite definir las operaciones y procesos unitarios adecuados en las plataformas para establecer las rutas de obtención de los productos.

Tabla 4. Procesos de transformación de residuos.

\begin{tabular}{|c|c|c|c|}
\hline Proceso & Definición & Principales productos & Referencias \\
\hline \multicolumn{4}{|c|}{ Físico } \\
\hline Densificación & $\begin{array}{l}\text { Compactación de las partículas de } \\
\text { biomasa sometiéndolas a altas } \\
\text { presiones para dar lugar a } \\
\text { productos sólidos }\end{array}$ & Pellets y briquetas & [73], [74] \\
\hline $\begin{array}{l}\text { Lixiviación o } \\
\text { extracción } \\
\text { sólido-líquido }\end{array}$ & $\begin{array}{l}\text { Separación de uno o más } \\
\text { componentes contenidos en una } \\
\text { fase sólida por una fase líquida o } \\
\text { disolvente }\end{array}$ & $\begin{array}{l}\text { Extractos: aceites, } \\
\text { azúcares, té y café }\end{array}$ & [75] \\
\hline \multicolumn{4}{|c|}{ Termoquímico } \\
\hline Combustión & $\begin{array}{l}\text { Serie de reacciones químicas por } \\
\text { las cuales los compuestos } \\
\text { orgánicos se oxidan hasta dióxido } \\
\text { de carbono y agua; se realiza a altas }\end{array}$ & $\begin{array}{lll}\text { Energía } & \text { térmica } & \text { y } \\
\text { eléctrica } & & \end{array}$ & [73], [76], [77] \\
\hline
\end{tabular}

Revista Facultad de Ingeniería (Rev. Fac. Ing.) Vol. 28 (53), pp. 7-32. Octubre-Diciembre 2019. Tunja-Boyacá, Colombia. L-ISSN: 0121-1129, e-ISSN: 2357-5328, DOI: https://doi.org/10.19053/01211129.v28.n53.2019.9705 


\begin{tabular}{|c|c|c|c|}
\hline Proceso & Definición & Principales productos & Referencias \\
\hline & $\begin{array}{l}\text { temperaturas (entre } 800{ }^{\circ} \mathrm{C} \text { y } 1000 \\
{ }^{\circ} \mathrm{C} \text { y utiliza aire como agente } \\
\text { oxidante }\end{array}$ & & \\
\hline Licuefacción & $\begin{array}{l}\text { Descomposición de los compuestos } \\
\text { macromoleculares en moléculas de } \\
\text { menor tamaño en presencia de un } \\
\text { catalizador adecuado }\end{array}$ & $\begin{array}{l}\text { Aceites, carbón y gases } \\
\text { para ser utilizados como } \\
\text { combustibles }\end{array}$ & [78], [79] \\
\hline Pirolisis & $\begin{array}{l}\text { Tratamiento de la biomasa a } \\
\text { temperaturas moderadas entre } 300 \\
{ }^{\circ} \mathrm{C} \text { y } 600{ }^{\circ} \mathrm{C} \text { en ausencia de oxígeno } \\
\text { para causar despolimerización } \\
\text { parcial del material. }\end{array}$ & $\begin{array}{l}\text { Gases volátiles } \\
\text { (monóxido y dióxido de } \\
\text { carbono, hidrógeno, } \\
\text { metano, etileno, etc.), } \\
\text { ácidos orgánicos y } \\
\begin{array}{l}\text { aldehídos, fenoles y } \\
\text { carbón }\end{array}\end{array}$ & [80], [81] \\
\hline Gasificación & $\begin{array}{l}\text { Combustión parcial de la biomasa } \\
\text { para producir gas y carbón }\end{array}$ & $\begin{array}{l}\text { Hidrogeno, monóxido y } \\
\text { dióxido de carbono, } \\
\text { metano y electricidad }\end{array}$ & {$[13],[78],[82]$} \\
\hline \multicolumn{4}{|c|}{ Químico } \\
\hline $\begin{array}{l}\text { Hidrólisis } \\
\text { química }\end{array}$ & $\begin{array}{l}\text { Reacción que implica la ruptura de } \\
\text { un enlace en una molécula con la } \\
\text { participación de agua usando un } \\
\text { catalizador químico; normalmente } \\
\text { ácidos y bases fuertes }\end{array}$ & $\begin{array}{l}\text { Azúcares, proteínas, } \\
\text { lípidos y carbohidratos }\end{array}$ & [83], [84], [85] \\
\hline $\begin{array}{l}\text { Conversión } \\
\text { supercrítica }\end{array}$ & $\begin{array}{l}\text { Utilización de fluidos supercríticos } \\
\text { para oxidar o extraer compuestos }\end{array}$ & $\begin{array}{l}\text { Aceites, antioxidantes, } \\
\text { alcaloides, aromas y } \\
\text { especies }\end{array}$ & [86], [87] \\
\hline \multicolumn{4}{|c|}{ Biológico } \\
\hline $\begin{array}{l}\text { Digestión } \\
\text { anaerobia }\end{array}$ & $\begin{array}{l}\text { Proceso biológico que sucede de } \\
\text { forma natural o artificial, donde la } \\
\text { materia orgánica se degrada en } \\
\text { ausencia de oxígeno }\end{array}$ & Biogás y lodos & [88], [89] \\
\hline $\begin{array}{l}\text { Digestión } \\
\text { aeróbica }\end{array}$ & $\begin{array}{l}\text { Estabilización bioquímica oxidativa } \\
\text { de lodos de las aguas residuales }\end{array}$ & $\begin{array}{l}\text { Dióxido de carbono y } \\
\text { agua }\end{array}$ & [90] \\
\hline Enzimólisis & $\begin{array}{l}\text { Proceso por medio del cual sucede } \\
\text { una reacción, donde los sustratos } \\
\text { se transforman en productos } \\
\text { utilizando enzimas r como } \\
\text { catalizadores }\end{array}$ & $\begin{array}{l}\text { Azúcares, proteínas, } \\
\text { lípidos y carbohidratos }\end{array}$ & [91] \\
\hline Fermentación & $\begin{array}{l}\text { Descomposición anaeróbica de la } \\
\text { glucosa vía glicolisis }\end{array}$ & $\begin{array}{l}\text { Alcoholes, enzimas y } \\
\text { ácidos }\end{array}$ & [92], [93] \\
\hline
\end{tabular}

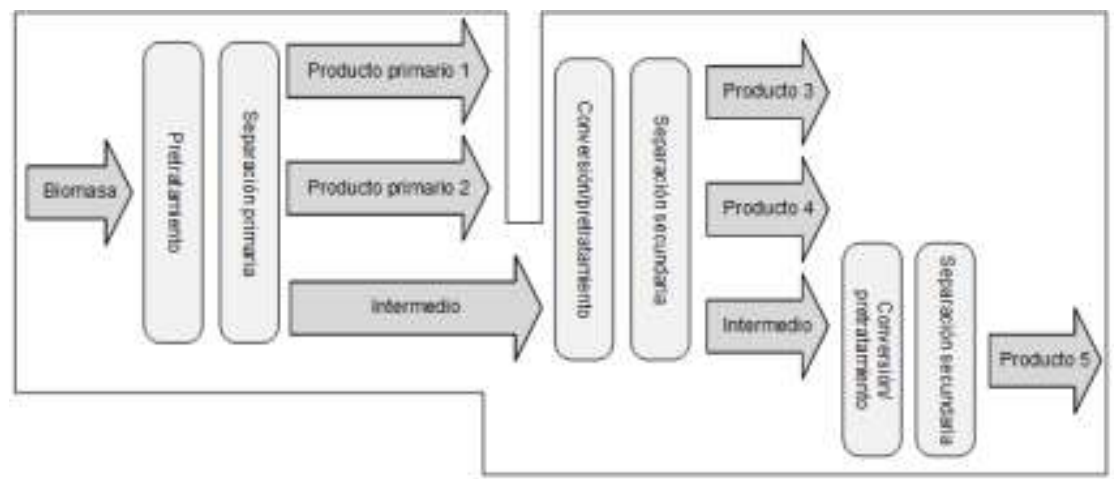

Fig. 1. Resumen esquemático de una biorrefinería. Adaptado de Jong, et al. [94].

Revista Facultad de Ingeniería (Rev. Fac. Ing.) Vol. 28 (53), pp. 7-32. Octubre-Diciembre 2019. Tunja-Boyacá, Colombia. L-ISSN: 0121-1129, e-ISSN: 2357-5328, DOI: https://doi.org/10.19053/01211129.v28.n53.2019.9705 


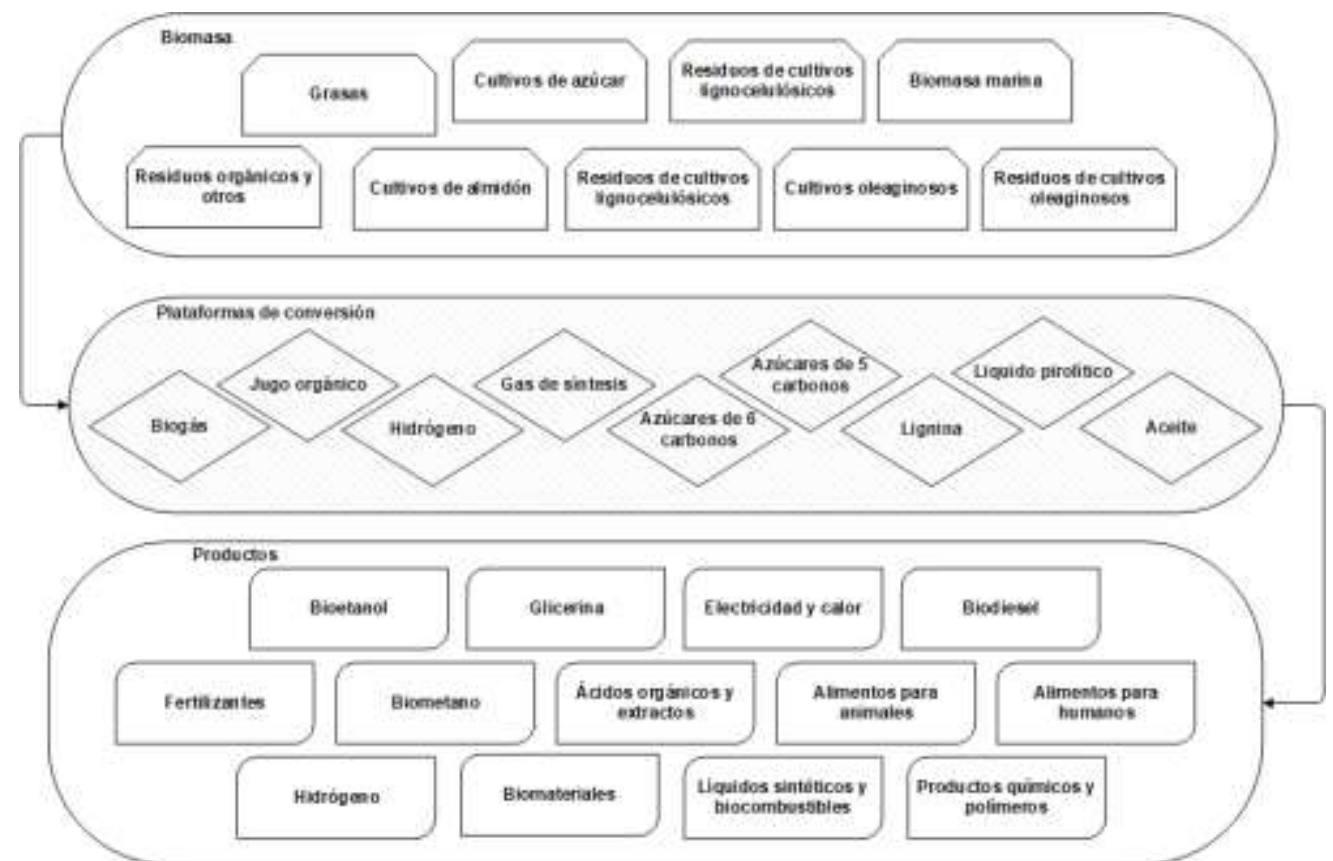

Fig. 2. Plataformas de conversión en una biorrefinería. Adaptado de IEA Bioenergy [9].

El diseño de procesos en el contexto de biorrefinerías para el aprovechamiento de materias primas residuales, debe implementar metodologías que apliquen la formulación, la síntesis, el análisis y la evaluación [95-100]. Adicionalmente, deberá aplicar técnicas de integración másica y energética $[101,102]$ para hacer uso eficiente de la energía [103] y de la masa [101].

Los métodos de diseño generalmente se clasifican en: métodos basados en conocimiento y métodos basados en la optimización. Los métodos basados en el conocimiento se centran en la representación y la organización del conocimiento del problema de diseño [104]. Probablemente, estos métodos sean uno de los más indicados para aplicar al diseño de biorrefinerías cuando se posee una amplia experiencia en procesos. Por otra parte, los métodos de optimización, permiten formular una síntesis de un diagrama de flujo en forma de un problema de optimización. Requiere una representación explícita o implícita de una superestructura de diagramas de flujo de procesos, entre las cuales se selecciona la solución óptima [104]. En este trabajo, la atención se enfoca en los métodos basados en el conocimiento. 
Los métodos basados en conocimiento poseen diferentes enfoques como la modificación evolutiva [105, 106], la descomposición jerárquica [107], el diseño dirigido a fenómenos [108], el enfoque basado en conflictos [109], la síntesis de procesos basada en termodinámica y el análisis de la estática [110], entre otros [104, 111]. Dentro de los anteriores, la descomposición jerárquica descrita por Douglas [112] es un enfoque adecuado para ser aplicada al diseño de biorrefinerías. Este enfoque descompone un problema de planimetría de procesos químicos muy grande y complejos en cinco niveles jerárquicos [113] (Fig. 3).

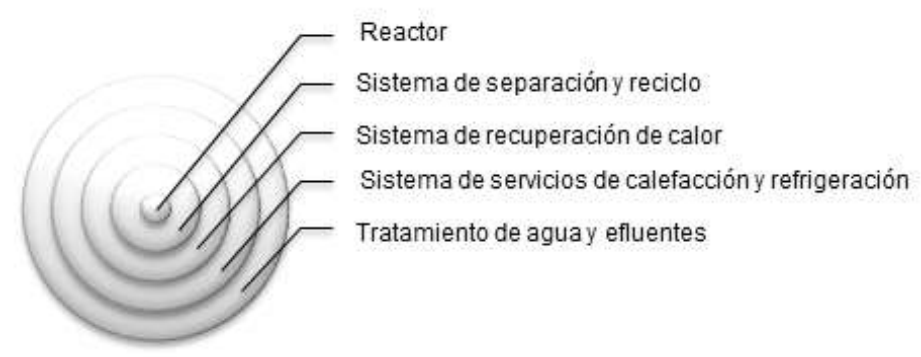

Fig. 3. Síntesis de proceso. Adaptado de Smith [114].

El diseño de este tipo de procesos para biorrefinerías deberá abordar la descomposición jerárquica no desde sus unidades (operaciones y procesos unitarios) sino desde cada proceso (sistema); analizando por separado y como indicadores medibles, las fases de separación y el reciclo desde la perspectiva de la recuperación energética y másica de todos los efluentes; adicionalmente el tratamiento de sus efluentes y el impacto al medio ambiente y la comunidad.

El método utilizado para el diseño de este tipo de procesos en el contexto de biorrefinerías deberá equilibrar tres objetivos fundamentales para ser sostenible: protección del medio ambiente, crecimiento económico y equidad social (Fig. 4) $[115,116]$. Estos objetivos deberán tener diferentes métricas orientadas a la evaluación del uso de los recursos, emisiones, efluentes y residuos, beneficio, valor e impuestos, inversiones, lugar de trabajo de las personas y la sociedad, entre otros [117]. Adicionalmente, deberá contemplar el análisis de la escala, las cadenas de abastecimiento y la simulación de procesos, entre otros aspectos. 


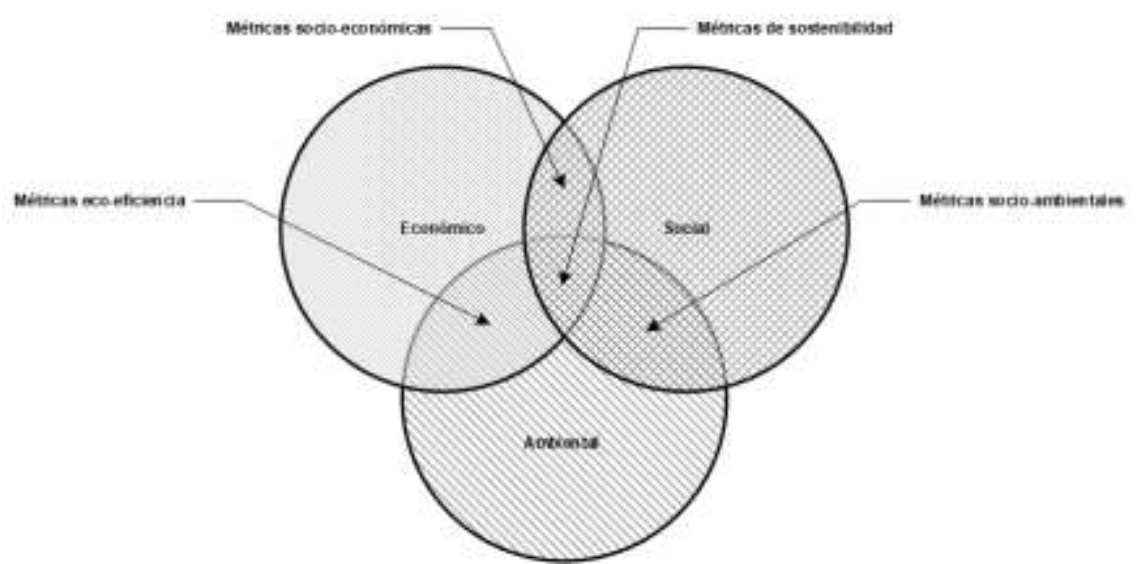

Fig. 4. Representación gráfica de la sostenibilidad. Adaptado de Sikdar [11].

La escala es una propiedad importante en el desarrollo de la tecnología de las biorrefinerías porque la mayoría de ese desarrollo deberá poder "ampliarse" [118]. Las biorrefinerías pueden ser clasificadas en pequeña y a gran escala [119]. Las biorrefinerías a pequeña escala son instalaciones que, por lo general, se ubican en áreas rurales y se basan en proceso biotecnológicos. Las biorrefinerías a gran escala están vinculadas a una red de plantas de procesamiento primario descentralizadas [120]. La escala puede impactar directamente en el beneficio económico de la biorrefinería debido a que cuanto mayor sea su tamaño, menor será la contribución de los costos de capital por unidad de producto [121]; este beneficio deberá ser evaluado desde la optimización en conjunto con los indicadores ambiental y social.

Con respecto a las cadenas de suministro, estas deberán tener en cuenta el problema de la ubicación de la biorrefinería. El problema de la ubicación deberá involucrar el análisis del flujo de materiales de los proveedores al proceso y el flujo de materiales del proceso a los clientes [122]. Desde este punto, el modelo de redes [123] es una herramienta aplicable al análisis de los flujos de materiales desde diferentes parámetros como los costos de transporte y de almacenamiento, entre otros [124].

La simulación de procesos aplicado a biorrefinerías es una herramienta útil que permite el diseño de un modelo operativo del sistema y realizar "experimentos virtuales" con el propósito de comprender el comportamiento del mismo [103]. Adicionalmente, la simulación puede entregar, información relacionada con 
indicadores tecno-económicos, ambientales y sociales; de esta forma, es posible evaluar alternativas de la biorrefinería en diferentes contextos. En especial, estos indicadores deberán hacer uso del proceso de la jerarquía analítica (AHP por sus siglas en inglés) [125] para ser estandarizados en un solo indicador que demuestre el mejor desempeño entre las múltiples alternativas de la biorrefinería.

Existen diferentes softwares de simulación que son utilizados debido a su ventaja y economía [103]. Uno de estos softwares es SuperPro Designer [126]. Este simulador posee múltiples ventajas para simular procesos de biorrefinerías debido a que incluye operaciones unitarias específicas para procesos biológicos como fermentadores; los cuales no tienen otros programas [127]. Adicionalmente, este simulador considera las particularidades de la programación de la producción en procesos por lotes, donde cada operación o proceso unitario se conforma de diferentes actividades y éstas a su vez poseen una programación secuencial (cargar, agitar, transferir, reaccionar, lavar, etc.).

La implementación de biorrefinerías es una alternativa para el aprovechamiento de las materias primas residuales urbanas, agrícolas y pecuarios; especialmente las biorrefinerías a pequeña escala pueden apoyar el desarrollo social y económico a nivel rural. Este tipo de complejos industriales no requieren un alto suministro de materias primas y su ubicación, permite procesar directamente la biomasa cerca de la fuente de generación [119]. Un ejemplo de biorrefinería a pequeña escala puede estar orientada al aprovechamiento de los residuos de la agroindustria del plátano (pseudotallo, raquis y frutos de rechazo) de forma simultánea para obtener diferentes productos [128-131]. Una etapa clave para un correcto aprovechamiento de este tipo de materia prima residual es el pretratamiento. En la Fig. 5, se presenta un proceso de pretratamiento para los residuos de plátano. Por lo general, los residuos del plátano se componen principalmente de residuos lignocelulósico y amiláceos. 


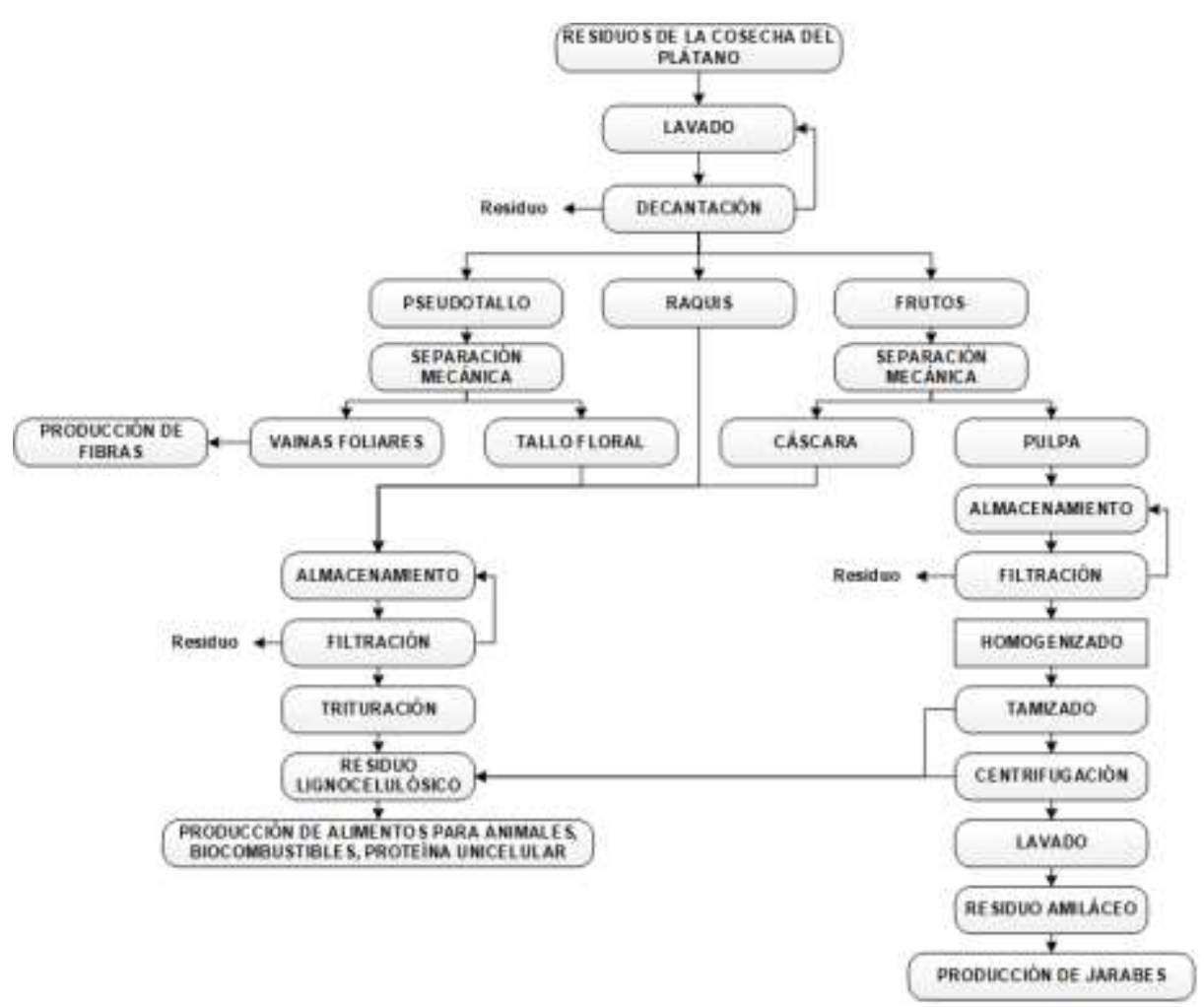

Fig. 5. Procesos de acondicionamiento de los residuos de la agroindustria del plátano.

\section{Conclusiones}

Existen múltiples procesos de transformación que pueden ser aplicados al aprovechamiento de la biomasa residual a nivel urbano y rural en el contexto de biorrefinerías.

El diseño deberá conformar el análisis de las cadenas de abastecimiento y de los procesos de transformación desde las evaluaciones tecno-económica, ambiental y social.

Es necesario aplicar metodologías de diseño y evaluación de procesos asistidas por simulación para evaluar en un menor tiempo, diferentes escenarios de una biorrefinerías adecuada para el aprovechamiento de la materia prima residual. Las futuras investigaciones en diseño de biorrefinerías deberán contemplar la intensificación de procesos (desarrollo de ingeniería que conduzca a una tecnología sustancialmente más pequeña, más limpia y con mayor eficiencia energética) [105], debido a las necesidades del mercado de tecnologías compactas que permitan ser fáciles de operar y eficientes másica y energéticamente. 
Estudios detallados de diseños de biorrefinerías que tengan en cuenta problemas de optimización para variables como la cantidad de biomasa residual que ingresa al sistema clasificada en dos o más corrientes (ejemplo, lignocelulósico y amiláceo); puede permitir un mayor rendimiento en los productos.

El aprovechamiento de las materias primas residuales (urbana, agrícola y pecuario) por medio de proyectos de inversión sostenibles en el contexto de biorrefinerías puede aportar al desarrollo rural con la generación de empleo, ingresos económicos adicionales y un menor impacto negativo al medio ambiente.

\section{CONTRIBUCIÓN DE LOS AUTORES}

La coordinación y organización de la información del documento estuvo a cargo de Óscar Julián Sánchez Toro. Luis Gerónimo Matallana Pérez apoyó el análisis de la información. La recopilación y análisis de la información, así como la escritura del documento, fueron realizadas por James Andrés Gómez Soto. Así mismo, todos los autores realizaron aportes significativos al documento y están de acuerdo con su publicación y manifiestan que no existen conflictos de interés en este estudio.

\section{AGRADECIMIENTOS}

Los autores agradecen al Departamento Administrativo de Ciencia, Tecnología e Innovación de Colombia (Colciencias) por el apoyo a través del proyecto de investigación "Diseño de una Biorrefinería para el Aprovechamiento de los Residuos Lignocelulósicos y Amiláceos de la Agroindustria del Plátano" (Convocatoria 757 para la financiación de doctorados nacionales, código del proyecto: 1640318); y a la Universidad de Caldas a través del proyecto de investigación: Desarrollo Básico de Procesos de Aprovechamiento de Residuos Agroindustriales y Urbanos Bajo el Concepto de Biorrefinerías (Código 0240518).

\section{REFERENCIAS}

[1] D. Hoornweg, and P. Bhada-Tata, "What a Waste. A Global Review of Solid Waste Management," 2012. Available at: http://siteresources.worldbank.org/INTURBANDEVELOPMENT/Resources/3363871334852610766/What a Waste2012 Final.pdf.

[2] Waste, "Waste Atlas," 2019. Available at: http://www.atlas.d-waste.com/. 
James Andrés Gómez-Soto, Óscar Julián Sánchez-Toro, Luis Gerónimo Matallana-Pérez

[3] J. F. Rojas, "Colombia entierra millones de pesos por no reciclar," El Colombiano, 2017. Available at: http://www.elcolombiano.com/especiales/que-hacer-con-la-basura/colombia-entierra-millones-de-pesospor-no-reciclar-FD3410601.

[4] DNP, "Disposición final de residuos sólidos. Informe nacional 2016," 2016. Available at: http://www.superservicios.gov.co/content/download/23144/187347.

[5] M. Mazzeo, F. Díaz, and L. Mejía, Aprovechamiento de Residuos de Cosecha y Poscosecha del Plátano. Colombia: Universidad de Caldas, 2015.

[6] J. Roberts, A. Cassula, P. Osvaldo, R. Dias, and J. Balestieri, "Assessment of dry residual biomass potential for use as alternative energy source in the party of General Pueyrredón, Argentina," Renewable and Sustainable Energy Reviews, vol. 41, pp. 568-583, 2015. https://doi.org/10.1016/i.rser.2014.08.066.

[7] IEA Bioenergy, "Bio-based Chemicals: Value Added Products from Biorefineries," 2012. Available at: http://www.ieabioenergy.com/publications/bio-based-chemicals-value-added-products-from-biorefineries/.

[8] R. Julio, J. Albet, C. Vialle, C. Vaca, and C. Sablayrolles, "Sustainable design of biorefinery processes: existing practices and new methodology," Biofuels, Bioproducts and Biorefining, vol. 11 (2), pp. 373-395, 2017. https://doi.org/10.1002/bbb.1749.

[9] IEA Bioenergy, "Biorefineries: adding value to the sustainable utilisation of biomasa," 2009. Available at: http://www.ieabioenergy.com/wp-content/uploads/2013/10/Task-42-Booklet.pdf.

[10] ICONTEC, Guía Técnica GTC 53-7. Aprovechamiento de Residuos Sólidos Orgánicos No Peligrosos. Bogotá, 2006.

[11] S. Sikdar, "Sustainable development and sustainability metrics," AlChE Journal, vol. 49 (8), pp. 1928-1932, 2003. https://doi.org/10.1002/aic.690490802.

[12] D. Ng, "Automated targeting for the synthesis of an integrated biorefinery," Chemical Engineering Journal, vol. 162 (1), pp. 67-74, 2010. https://doi.org/10.1016/j.cej.2010.04.061.

[13] F. Gírio, S. Marques, F. Pinto, A. Oliveira, P. Costa, A. Reis, and P. Moura, "Biorefineries in the World," Biorefineries. Targeting Energy, High Value Products and Waste Valorisation. Suiza: Springer, 2017, pp. 227-278.

[14] RFA, "World fuel ethanol production," 2019. Available at: http://www.ethanolrfa.org/resources/industry/statistics/\#1454099103927-61e598f7-7643.

[15] A. Demirbaş, Biorefineries For Biomass Upgrading Facilities. Reino Unido: Springer, 2010.

[16] EurObserv'ER, "Biofuels barometer 2015," 2015. Available at: https://www.eurobserv-er.org/biofuelsbarometer-2015/.

[17] J. Moncada, V. Aristizábal, and C. Cardona, "Design strategies for sustainable biorefineries," Biochemical Engineering Journal, vol. 116 (Supp. C), pp. 122-134, 2016. https://doi.org/10.1016/..bej.2016.06.009.

[18] Fedebiocombustibles, "Estadísticas. Alcohol carburante (etanol) y biodiesel," 2019. Available at: http://www.fedebiocombustibles.com/.

[19] Ellen Macarthur Foundation, "Towards the circular economy," 2013. Available at: https://www.ellenmacarthurfoundation.org/assets/downloads/publications/Ellen-MacArthur-FoundationTowards-the-Circular-Economy-vol.1.pdf.

[20] J. Arango, C. Collazos, F. Gutiérrez Vela, and L. Castillo, "A systematic review of geolocated pervasive games: A perspective from game development methodologies, software metrics and linked open data," Design, User Experience, and Usability: Designing Pleasurable Experiences. Canadá : Springer, 2017, pp. 335-346.

[21] J. Pérez, and L. Muñoz, "What can't be ignored in service quality evaluation: Application contexts, tools and factors," Revista Facultad de Ingeniería Universidad de Antioquia, vol. 72 pp. 145-160, 2014.

[22] X. Wen, Q. Luo, H. Hu, N. Wang, Y. Chen, J. Jin, Y. Hao, G. Xu, F. Li, and W. Fang, "Comparison research on waste classification between China and the EU, Japan, and the USA," Journal of Material Cycles and Waste Management, vol. 16 (2), pp. 321-334, 2014. https://doi.org/10.1007/s10163-013-0190-1.

[23] EPA, "Resource Conservation and Recovery Act (RCRA) Overview," 2018. Available at: https://www.epa.gov/rcra/resource-conservation-and-recovery-act-rcra-overview.

[24] Comisión de las Comunidades Europeas, Decisión de la Comisión que sustituye a la Decisión 94/3/CE. Bélgica, 2000.

[25] Comisión Nacional de Regulación, Reglamento (CE) No 574/2004 de la Comisión. Bélgica, 2004.

[26] Ministerio de Ambiente y Desarrollo Sostenible de Colombia, Decreto No. 2811. Bogotá, 1974.

[27] Ministerio de Ambiente y Desarrollo Sostenible de Colombia, Decreto No. 2104. Bogotá, 1983.

[28] Ministerio de Ambiente Vivienda y Desarrollo Territorial de Colombia, Decreto No. 838. Bogotá, 2005.

[29] Ministerio de Desarrollo Económico de Colombia, Decreto No. 1713. Bogotá, 2002.

[30] ICONTEC, Norma Técnica GTC 24. Gestión Ambiental. Residuos Sólidos. Guía para la Separación en la Fuente. Bogotá, 2009.

[31] A. Demirbaş, "Waste management, waste resource facilities and waste conversion processes," Energy Conversion and Management, vol. 52 (2), pp. 1280-1287, 2011. https://doi.org/10.1016/i.enconman.2010.09.025. 
Residuos urbanos, agrícolas y pecuarios en el contexto de las biorrefinerías

[32] D. Polanía, "Política para la gestión integral de residuos sólidos 2016-2030," 2017. Available at: http://www.andi.com.co/Uploads/3.\%20Socializaci\%C3\%B3n\%20CONPES\%203874\%20ANDI.pdf.

[33] A. Nizami, K. Shahzad, M. Rehan, O. Ouda, M. Khan, I. Ismail, T. Almeelbi, J. Basahi, and A. Demirbas, "Developing waste biorefinery in Makkah: a way forward to convert urban waste into renewable energy," Applied Energy, vol. 186, pp. 189-196, 2017. https://doi.org/10.1016/i.apenergy.2016.04.116.

[34] Infobae, "El atlas de los desperdicios: los países que más basura producen," 2017. Available at: http://www.infobae.com/economia/rse/2017/05/01/el-atlas-de-los-desperdicios-los-paises-que-masbasura-producen/.

[35] Concejo de Bogotá, "Proyecto de Acuerdo 113", 2011. Available at: http://www.alcaldiabogota.gov.co/sisjur/normas/Norma1.jsp?i=41936.

[36] DNP, "Disposición final de residuos sólidos. Informe nacional," 2017. Available at: https://www.superservicios.gov.co/sala-de-prensa/publicaciones.

[37] L. L. Becerra, "El modelo de negocio que construye casas a partir de bloques de plástico," La República, 2017. Available at: https://www.larepublica.co/responsabilidad-social/el-modelo-de-negocio-queconstruye-casas-a-partir-de-bloques-de-plastico-2537636.

[38] M. Okan, H. Aydin, and M. Barsbay, "Current approaches to waste polymer utilization and minimization: A review," Journal of Chemical Technology \& Biotechnology, vol. 94 (1), pp. 8-21, 2019. https://doi.org/10.1002/jctb.5778.

[39] FAO, "FAOSTAT: Food and agriculture data," 2019. Available at: http://www.fao.org/faostat/es/\#data.

[40] H. Escalante, J. Orduz, H. Zapata, M. Cardona, and M. Duarte, "Atlas del potencial energético de la biomasa residual en Colombia," $2009 . \quad$ Available http://www1.upme.gov.co/sites/default/files/article/1768/files/Atlas\%20de\%20Biomasa\%20Residual\%20C olombia .pdf.

[41] Agronet, "Anuario Estadístico del Sector Agropecuario. Base Agricola EVA 2007-2017," 2017. Available at: http://www.agronet.gov.co/estadistica/Paginas/default.aspx.

[42] T. Hicks, and C. Verbeek, "Protein-Rich by-Products: Production Statistics, Legislative Restrictions, and Management Options," Protein Byproducts. Reino Unido: Academic Press, 2016, pp. 1-18.

[43] B. Mahro, and M. Timm, "Potential of biowaste from the food industry as a biomass resource," Engineering in Life Sciences, vol. 7 (5), pp. 457-468, 2007. https://doi.org/10.1002/elsc.200620206.

[44] DANE, "Encuesta de sacrificio de ganado," $2018 . \quad$ Available at: https://www.dane.gov.co/index.php/estadisticas-por-tema/agropecuario/encuesta-de-sacrificio-deganado.

[45] FENAVI, "El sector avícola en Colombia creció 4,5\% en 2018," 2018. Available at: http://fenavi.org/comunicados-de-prensa/el-sector-avicola-crecio-45-en-2018/.

[46] Hubbard Breeders, "Ultra-Yield," 2007. Available at: http://www.thepoultrysite.com/downloads/single/48/.

[47] M. Bragachini, I. Huerga, D. Mathier, and N. Sosa, "Residuos pecuarios: una problemática que puede transformarse en oportunidad," 2013. Available at: http://inta.gob.ar/documentos/residuos-pecuarios-unaproblematica-que-puede-transformarse-en-oportunidad.

[48] R. Tester, J. Karkalas, and Q. Xin, "Starch-composition, fine structure and architecture," Journal of Cereal Science, vol. 39 (2), pp. 151-165, 2004. Doi: https://doi.org/10.1016/j.jcs.2003.12.001

[49] M. van der Maarel, B. van der Veen, J. Uitdehaag, H. Leemhuis, and L. Dijkhuizen, "Properties and applications of starch-converting enzymes of the $\alpha$-amylase family," Journal of Biotechnology, vol. 94 (2), pp. 137-155, 2002. https://doi.org/10.1016/S0168-1656(01)00407-2.

[50] G. Dongowski, A. Lorenz, and H. Anger, "Degradation of pectins with different degrees of esterification by bacteroides thetaiotaomicron isolated from human gut flora," Applied and Environmental Microbiology, vol. 66 (4), pp. 1321-1327, 2000. https://doi.org/10.1128/AEM.66.4.1321-1327.2000.

[51] B. Thakur, R. Singh, A. Handa, and M. Rao, "Chemistry and Uses of Pectin-A Review," Critical Reviews in Food Science and Nutrition, vol. 37 (1), pp. 47-73, 1997. https://doi.org/10.1080/10408399709527767.

[52] P. Sriamornsak, "Chemistry of pectin and its pharmaceutical uses: A review," Silpakorn University International Journal, vol. 3 (1-2), pp. 206-228, 2003.

[53] H. Yokoi, T. Obita, J. Hirose, S. Hayashi, and Y. Takasaki, "Flocculation properties of pectin in various suspensions," Bioresource Technology, vol. 84 (3), pp. 287-290, 2002. https://doi.org/10.1016/S09608524(02)00023-8.

[54] H. Owens, H. Lotzkar, R. Merrill, and M. Peterson, "Viscosities of pectin solutions," Journal of the American Chemical Society, vol. 66 (7), pp. 1178-1182, 1944. https://doi.org/10.1021/ja01235a035.

[55] R. Ciriminna, A. Fidalgo, R. Delisi, L. Ilharco, and M. Pagliaro, "Pectin production and global market," Agro FOOD Industry Hi Tech, vol. 27 (5), pp. 17-20, 2016.

[56] A. Nesterenko, I. Alric, F. Silvestre, and V. Durrieu, "Vegetable proteins in microencapsulation: A review of recent interventions and their effectiveness," Industrial Crops and Products, vol. 42 pp. 469-479, 2013. https://doi.org/10.1016/.indcrop.2012.06.035.

[57] P. Shewry, and R. Casey, "Introduction. Seed Proteins," Seed Proteins. Alemania: Springer Science+Business Media, 1999, pp. 1-10.

Revista Facultad de Ingeniería (Rev. Fac. Ing.) Vol. 28 (53), pp. 7-32. Octubre-Diciembre 2019. Tunja-Boyacá, Colombia. L-ISSN: 0121-1129, e-ISSN: 2357-5328, DOI: https://doi.org/10.19053/01211129.v28.n53.2019.9705 
James Andrés Gómez-Soto, Óscar Julián Sánchez-Toro, Luis Gerónimo Matallana-Pérez

[58] E. Fahy, D. Cotter, M. Sud, and S. Subramaniam, "Lipid classification, structures and tools," Biochimica et Biophysica Acta (BBA) - Molecular and Cell Biology of Lipids, vol. 1811 (11), pp. 637-647, 2011. https://doi.org/10.1016/i.bbalip.2011.06.009.

[59] F. Gunstone, Oils and Fats in the Food Industry. Reino Unido: Blackwell Publishing, 2008.

[60] D. Ferrier, and R. Harvey, Lippincott's Illustrated Reviews: Biochemistry, 6 ed. Estados Unidos: Lippincott Williams \& Wilkins, 2014.

[61] Ó. Sánchez, and S. Montoya, "Production of Bioethanol From Biomass: An overview," Biofuel Technologies. Alemania: Springer, 2013, pp. 397-441.

[62] P. Mohanty, K. Pant, and R. Mittal, "Hydrogen generation from biomass materials: challenges and opportunities," WIREs Energy \& Environment, vol. 4 (2), pp. 139-155, 2014. https://doi.org/10.1002/wene.111.

[63] H. Chen, Biotechnology of Lignocellulose. Theory and Practice. China: Chemical Industry Press and Springer, 2014.

[64] S. Li, L. Bashline, L. Lei, and Y. Gu, "Cellulose synthesis and its regulation," The Arabidopsis Book, pp. 121, 2014. Doi: https://doi.org/10.1199/tab.0169.

[65] Y. Meng, Z. Pang, and C. Dong, "Enhancing cellulose dissolution in ionic liquid by solid acid addition," Carbohydrate Polymers, vol. 163, pp. 317-323, 2017. https://doi.org/10.1016/i.carbpol.2017.01.085.

[66] Ó. Sánchez, and C. Cardona, Producción de Alcohol Carburante. Una Alternativa para el Desarrollo Agroindustrial. Manizales: Gobernación de Caldas. Secretaría de Educación. Programa de las Naciones Unidadas para el Desarrollo (PNUD). Universidad Nacional de Colombia, 2007.

[67] H. Scheller, and P. Ulvskov, "Hemicelluloses," Annual Review of Plant Biology, vol. 61 pp. 263-289, 2010. https://doi.org/10.1146/annurev-arplant-042809-112315.

[68] J. Gómez, Ó. Sánchez, and X. Benavides, "Análisis de patentes como aproximación al diseño conceptual del proceso de obtención de jarabe de lactosuero," Revista de Investigacion Desarrollo e Innovacion, vol. 7 (2), pp. 331-353, 2017. https://doi.org/10.19053/20278306.v7.n2.2017.5453.

[69] J. Gómez, and Ó. Sánchez, "Producción de galactooligosacáridos: alternativa para el aprovechamiento del lactosuero. Una revisión," Ingeniería y Desarrollo, vol. 37 (1), pp. 129-158, 2019. http://dx.doi.org/10.14482/inde.37.1.637.

[70] AB Newswire, "Whey protein ingredients market global industry analysis, key vendors, opportunity and forecast 2018 to 2023," 2018. Available at: http://www.abnewswire.com/pressreleases/whey-proteiningredients-market-global-industry-analysis-key-vendors-opportunity-and-forecast-2018-to2023 180863.html.

[71] R. Kumar, I. Sundari, S. Sen, N. Dasgupta, and R. Chidambaram, "Animal fat and vegetable oil-based platform chemical ciorefinery," Platform Chemical Biorefinery. Países Bajos: Elsevier, 2016, pp. 361-377.

[72] S. Pérez, and D. Samain, "Structure and Engineering of Celluloses," Advances in Carbohydrate Chemistry and Biochemistry. Reino Unido: Elsevier, 2010, pp. 25-116.

[73] J. Carrasco, "Combustión directa de la biomasa," 2007. Available at: http://api.eoi.es/api v1 dev.php/fedora/asset/eoi:45279/componente45278.pdf.

[74] R. Isemin, A. Mikhalev, D. Klimov, P. Grammelis, N. Margaritis, D. Kourkoumpas, and V. Zaichenko, "Torrefaction and combustion of pellets made of a mixture of coal sludge and straw," Fuel, vol. 210 (Supp. C), pp. 859-865, 2017. https://doi.org/10.1016/j.fuel.2017.09.032.

[75] A. Ibarz, and G. Barbosa, Unit Operations in Food Engineering. Estados Unidos: CRC Press LLC, 2003.

[76] A. Demirbaş, "Combustion of biomass," Energy Sources, Part A: Recovery, Utilization, and Environmental Effects, vol. 29 (6), pp. 549-561, 2007. https://doi.org/10.1080/009083190957694.

[77] T. Mendiara, A. Pérez, M. Izquierdo, A. Abad, L. de Diego, F. García, P. Gayán, and J. Adánez, "Chemical looping combustion of different types of biomass in a 0.5kWth unit," Fuel, vol. 211 (Supp. C), pp. 868-875, 2018. https://doi.org/10.1016/.juel.2017.09.113.

[78] A. Demirbaş, Biofuels. Securing the Planet's Future Energy Needs. Reino Unido: Springer, 2009.

[79] L. Jasiūnas, T. Pedersen, S. Toor, and L. Rosendahl, "Biocrude production via supercritical hydrothermal co-liquefaction of spent mushroom compost and aspen wood sawdust," Renewable Energy, vol. 111 (Supp. C), pp. 392-398, 2017. https://doi.org/10.1016/j.renene.2017.04.019.

[80] C. Amen, H. Pakdel, and C. Roy, "Production of monomeric phenols by thermochemical conversion of biomass: A review," Bioresource Technology, vol. 79 (3), pp. 277-299, 2001. https://doi.org/10.1016/S09608524(00)00180-2.

[81] L. Clements, and D. Van Dyne, "The Lignocellulosic Biorefinery. A Strategy for Returning to a Sustainable Source of Fuels and Industrial Organic Chemicals," Biorefineries. Industrial Processes and Products: Status Quo and Future Directions. Alemania: Wiley-VCH, 2006, pp. 115-128.

[82] O. Norouzi, F. Safari, S. Jafarian, A. Tavasoli, and A. Karimi, "Hydrothermal gasification performance of Enteromorpha intestinalis as an algal biomass for hydrogen-rich gas production using $\mathrm{Ru}$ promoted $\mathrm{Fe}-$ $\mathrm{Ni} / \mathrm{Y}$-Al2O3 nanocatalysts," Energy Conversion and Management, vol. 141 (Supp. C), pp. 63-71, 2017. https://doi.org/10.1016/i.enconman.2016.04.083.

Revista Facultad de Ingeniería (Rev. Fac. Ing.) Vol. 28 (53), pp. 7-32. Octubre-Diciembre 2019. Tunja-Boyacá, Colombia. L-ISSN: 0121-1129, e-ISSN: 2357-5328, DOI: https://doi.org/10.19053/01211129.v28.n53.2019.9705 
Residuos urbanos, agrícolas y pecuarios en el contexto de las biorrefinerías

[83] J. Binder, and R. Raines, "Fermentable sugars by chemical hydrolysis of biomass," Proceedings of the National Academy of Sciences, vol. 107 (10), pp. 4516-4521, 2010. https://doi.org/10.1073/pnas.0912073107.

[84] S. Morales, "Hidrólisis Ácida de Celulosa y Biomasa Lignocelulósica Asistida con Líquidos lónicos," Doctoral Thesis, Departamento de Química-Física Aplicada, Universidad Autónoma de Madrid, España, 2015.

[85] P. Kumar, D. Barrett, M. Delwiche, and P. Stroeve, "Methods for pretreatment of lignocellulosic biomass for efficient hydrolysis and biofuel production," Industrial \& Engineering Chemistry Research, vol. 48 (8), pp. 3713-3729, 2009. https://doi.org/10.1021/ie801542g.

[86] M. Esquível, and M. Bernardo, "El uso de fluidos supercríticos en la industria de aceites alimentarios," Grasas y Aceites, vol. 44 (1), pp. 1-5, 1993. https://doi.org/10.3989/gya.1993.v44.i1.

[87] R. Velasco, H. Villada, and J. Carrera, "Aplicaciones de los fluidos supercríticos en la agroindustria," Información tecnológica, vol. 18 (1), pp. 53-66, 2007. http://dx.doi.org/10.4067/S071807642007000100009 .

[88] V. Nallathambi Gunaseelan, "Anaerobic digestion of biomass for methane production: A review," Biomass and Bioenergy, vol. 13 (1), pp. 83-114, 1997. https://doi.org/10.1016/S0961-9534(97)00020-2.

[89] P. Vandevivere, L. De Baere, and W. Verstraete, "Types of Anaerobic Digesters for Solid Wastes," Biomethanization of the Organic Fraction of Municipal Solid Wastes. Reino Unido: IWA Publishing, 2003, p. 31.

[90] N. Shammas, and L. Wang, "Aerobic Digestion," Biological Treatment Processes. Estados Unidos: Humana Press, 2009, pp. 635-667.

[91] S. Keshk, "Cellulase application in Enzymatic Hydrolysis of Biomass," New and Future Developments in Microbial Biotechnology and Bioengineering. Países Bajos: Elsevier, 2016, pp. 185-191.

[92] Khan, "Fermentation and anaerobic respiration," 2017. Available at: https://www.khanacademy.org/science/biology/cellular-respiration-and-fermentation/variations-on-cellularrespiration/a/fermentation-and-anaerobic-respiration.

[93] Ó. Sánchez, M. Ortiz, and L. Betancourt, "Obtención de ácido cítrico a partir de suero de leche por fermentación con Aspergillus spp," Revista Colombiana de Biotecnología, vol. 6 (1), pp. 43-54, 2004. https://doi.org/10.15446/rev.colomb.biote.

[94] E. Jong, R. van Ree, R. van Tuil, and W. Elbersen, "Biorefineries for the Chemical Industry. A Dutch Point of View," Biorefineries - Industrial Processes and Products. Alemania: Wiley-VCH, 2006, pp. 85-111.

[95] L. Puigjaner, P. Ollero, C. De Prada, and L. Jiménez, Estrategias de Modelado, Simulación y Optimización de Procesos Químicos. España: Editorial Síntesis, 2006.

[96] Ó. Sánchez, and C. Cardona, "Conceptual design of cost-effective and environmentally-friendly configurations for fuel ethanol production from sugarcane by knowledge-based process synthesis," Bioresource Technology, vol. 104, pp. 305-314, 2012. https://doi.org/10.1016/j.biortech.2011.08.125.

[97] J. Sirola, "Industrial Applications of Chemical Process Synthesis," in Advances in Chemical Engineering. Estados Unidos: Academic Press, 1996, pp. 1-62.

[98] J. Sacramento, "A methodology for evaluating the sustainability of biorefineries: framework and indicators," Biofuels, Bioproducts and Biorefining, vol. 6 (1), pp. 32-44, 2012. http://dx.doi.org/10.1002/bbb.335.

[99] J. Sacramento, F. Navarro, and L. Vilchiz, "Evaluating the sustainability of biorefineries at the conceptual design stage," Chemical Engineering Research and Design, vol. 107 (Supp. C), pp. 167-180, 2016. https://doi.org/10.1016/i.cherd.2015.10.017.

[100] R. Smith, G. Ruiz, and M. Gonzalez, "Using GREENSCOPE indicators for sustainable computer-aided process evaluation and design," Computers \& Chemical Engineering, vol. 81, pp. 272-277, 2015. https://doi.org/10.1016/i.compchemeng.2015.04.020.

[101] M. El-Halwagi, Process Integration. Estados Unidos: Elsevier, 2006.

[102] I. Kemp, Pinch Analysis and Process Integration. User Guide on Process Integration for the Efficient Use of Energy. Reino Unido: Elsevier, 2007.

[103]A. Dimian, Integrated Design and Simulation of Chemical Processes. Países Bajos: Elsevier, 2014.

[104] X. Li, "Conflict-based Method for Conceptual Process Synthesis," Doctoral Thesis, Lappeenranta University of Technology, Lappeenranta, Finlandia, 2004.

[105] Q. Chen, and I. Grossmann, "Recent developments and challenges in optimization-based process synthesis," Annual Review of Chemical and Biomolecular Engineering, vol. 8 (1), pp. 249-283, 2017. https://doi.org/10.1146/annurev-chembioeng-080615-033546.

[106] A. Westerberg, and G. Stephanopoulos, "Studies in process synthesis I: Branch and bound strategy with list techniques for the synthesis of separation schemes," Chemical Engineering Science, vol. 30 (8), pp. 963-972, 1975. https://doi.org/10.1016/0009-2509(75)80063-7.

[107]J. Douglas, "A hierarchical decision procedure for process synthesis," AlChE Journal, vol. 31 (3), pp. 353362, 1985. https://doi.org/10.1002/aic.690310302.

[108] I. Gavrila, and P. ledema, "Phenomena-driven process design, a knowledge-based approach," Computers \& Chemical Engineering, vol. 20, pp. S103-S108, 1996. https://doi.org/10.1016/0098-1354(96)00028-2.

Revista Facultad de Ingeniería (Rev. Fac. Ing.) Vol. 28 (53), pp. 7-32. Octubre-Diciembre 2019. Tunja-Boyacá, Colombia. L-ISSN: 0121-1129, e-ISSN: 2357-5328, DOI: https://doi.org/10.19053/01211129.v28.n53.2019.9705 
[109]X. Li, and A. Kraslawski, "Conceptual process synthesis: past and current trends," Chemical Engineering and Processing, vol. 43 (5), pp. 589-600, 2004. https://10.1016/i.cep.2003.05.002.

[110]Ó. Sánchez, "Síntesis de Esquemas Tecnológicos Integrados para la Producción Biotecnológica de Alcohol Carburante a partir de Tres Materias Primas Colombianas," Doctoral Thesis, Departamento de Ingeniería Química, Universidad Nacional de Colombia, Manizales, Caldas, 2008.

[111]D. Ng, V. Pham, M. El-Halwagi, A. Jiménez, and H. Dennis, "A Hierarchical Approach to the Synthesis and Analysis of Integrated Biorefineries," Design for Energy and the Environment. Estados Unidos: Taylor and Francis Group, 2010, p. 1101.

[112] J. Douglas, Conceptual Desing of Chemical Processes. Singapur: McGraw-Hill Book Company, 1988.

[113]Z. Yuan, B. Chen, and R. Gani, "Applications of process synthesis: Moving from conventional chemical processes towards biorefinery processes," Computers \& Chemical Engineering, vol. 49, pp. 217-229, 2013. https://doi.org/10.1016/..compchemeng.2012.09.020.

[114] R. Smith, Chemical Process Design and Integration. Reino Unido: John Wiley \& Sons, Ltd, 2005.

[115]M. El-Halwagi, Sustainable Design Through Process Integration. Reino Unido: Elsevier, 2012.

[116] S. Sikdar, "Journey towards sustainable development: A role for chemical engineers," Environmental Progress, vol. 22 (4), pp. 227-232, 2003. https://doi.org/10.1002/ep.670220409.

[117] Ichem ${ }^{\mathrm{E}}$, "The Sustainability Metrics," $2003 . \quad$ Available at: http://nbis.org/nbisresources/metrics/triple bottom line indicators process industries.pdf.

[118] C. Hamelinck, G. Hooijdonk, and A. Faaij, "Ethanol from lignocellulosic biomass: techno-economic performance in short-, middle- and long-term," Biomass and Bioenergy, vol. 28 (4), pp. 384-410, 2005. https://doi.org/10.1016/j.biombioe.2004.09.002.

[119] S. Serna, G. Aroca, and C. Cardona, "Small-Scale Biorefineries: Future and Perspectives," Biorefineries Concepts, Advancements and Research. Estados Unidos: Nova Science Publishers, 2017, pp. 39-71.

[120] V. Aristizábal, and C. Cardona, "Methods for designing and assessing biorefineries: Review," Biofuels, Bioproducts and Biorefining, pp. 1-20, 2018. https://doi.org/10.1002/bbb.1961.

[121]M. Jack, "Scaling laws and technology development strategies for biorefineries and bioenergy plants," $\begin{array}{llllll}\text { Bioresource Technology, } & \text { vol. } 100 \quad \text { (24), pp. } & 6324-6330, & 2009 .\end{array}$ https://doi.org/10.1016/j.biortech.2009.06.109.

[122] A. Duarte, W. Sarache, and Y. Costa, "A facility-location model for biofuel plants: Applications in the Colombian context," Energy, vol. 72, pp. 476-483, 2014. Doi: https://doi.org/10.1016/j.energy.2014.05.069.

[123] H. Taha, Investigación de Operaciones, 9 ed. México: Pearson Education, 2012.

[124]A. Duarte, "Metodología para la Localización de Instalaciones de Producción de Biocombustibles con Enfoque de Cadenas de Suministro. Aplicaciones en el Contexto Colombiano," Doctoral Thesis, Departamento Ingeniería Industrial, Universidad Nacional de Colombia, Manizales, Caldas, 2015.

[125] T. Saaty, and L. Vargas, Models, Methods, Concepts \& Applications of the Analytic Hierarchy Process, 2 ed. Luxemburgo: Springer Science+Business Media, 2012.

[126] Intelligen Inc., "SuperPro Designer v10," 2019. Available at: http://www.intelligen.com/index.html.

[127] N. Alnur Auli, M. Sakinah, A. Mustafa Al-Bakri, H. Kamarudin, and M. Norazian, "Simulation of xylitol production: a review," Australian Journal of Basic and Applied Sciences, vol. 7 (5), pp. 366-372, 2013.

[128]D. Suárez, O. Marín, J. Ortiz, A. Puentes, L. Ballesteros, and M. Suárez, "Biotechnology as a tool for the agroindustrial exploitation of residues of the chain of Musa spp," Chemical Engineering Transactions, vol. 64, pp. 571-576, 2018. https://doi.org/10.3303/CET1864096.

[129]E. Cadena, M. Vélez, J. Santa, and V. Otálvaro, "Natural fibers from plantain pseudostem (Musa paradisiaca) for use in fiber-reinforced composites," Journal of Natural Fibers, vol. 14 (5), pp. 678-690, 2017. https://doi.org/10.1080/15440478.2016.1266295.

[130]E. Oluyemi, J. Oyekunle, and S. Olasoji, "A comparative study of the removal of heavy metal ions from synthetic wastewaters using different adsorbents," Adsorption Science \& Technology, vol. 27 (5), pp. 493501, 2009. https://doi.org/10.1260/0263-6174.27.5.493.

[131]E. Inam, U. Etim, E. Akpabio, and S. Umoren, "Simultaneous adsorption of lead (II) and 3,7Bis(dimethylamino)-phenothiazin-5-ium chloride from aqueous solution by activated carbon prepared from plantain peels," Desalination and Water Treatment, vol. 57 (14), pp. 6540-6553, 2016. https://doi.org/10.1080/19443994.2015.1010236. 